-a constituent of cozymase-brings about such an inhibition. Results given in Table 1 show that if cozymase is incubated in presence of a small quantity of brain suspension together with 0.1 per cent nicotinamide, very little breakdown of the cozymase takes place. Results given in Table 3 show the stimulating action of nicotinamide on the oxygen ronarmmtion, when this is added to a kidney preparation of lactic dehydrogenase to which cozymase and brain suspension have also been added. The effect of nicotinamide on the activity of brain tissue itself, in the presence of lactate and cozymase, is shown in Table 4, where typical results obtained by the technique of Quastel and Wheatley ${ }^{1}$ are given.

\section{TABLR 4}

Brain system consists of $1 \mathrm{ml}$. brain suspension ( $1.6 \mathrm{gm}$. chopped rat brain in $16 \mathrm{ml}$. Locke solution), cozymase and sodium cyanide $(0.05 \mathrm{M}$.) in bicarbonate-Locke medium ( $p \mathrm{H} 7 \cdot 4)$. Sodium ferricyanide $(0.2 \mathrm{ml}$. 10 per cent) was added, in an atmosphere of 95 per cent nitrogen +5 per cent $\mathrm{CO}_{2}$, and the evolution of $\mathrm{CO}_{2}$ measured.

$$
\begin{aligned}
& \begin{array}{l}
\mathrm{CO}_{2} \text { output at } \\
37^{\circ} \text { in } 1 \text { hour }
\end{array}
\end{aligned}
$$

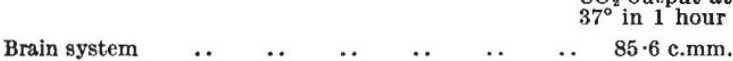

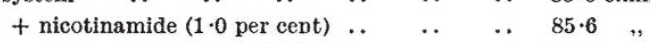

$$
\begin{aligned}
& + \text { sodium lactate }(0 \cdot 13 \text { M.) } \quad \text {. } \quad \ldots \quad \ldots \quad 107 \cdot 5 \quad \text {, } \\
& \text { + sodium lactate }(0.13 \text { M.) + nicotinamide } 357.8 \text {, }
\end{aligned}
$$

These results make it clear that nicotinamide exerts an inhibitory effect on the breakdown of cozymase by a tissue nucleotidase. A few experiments have indicated considerable specificity of nicotinamide in this respect. Nicotinic acid at the concentrations we have used has no effect. It would not be expected that nicotinamide would effect any stimulation of the respiration of intact tissues obtained from healthy animals since in such tissues the breakdown of cozymase is balanced by its synthesis. Experiment shows that $0 \cdot 1$ per cent nicotinamide does not increase the respiration of intact brain slices in a lactate medium. There is, on the contrary, a small inhibition of the respiration such as has already been reported by Baker, Fazekas and Himwich ${ }^{2}$.

This demonstration of the action of nicotinamide in protecting cozymase from breakdown, possibly by competition for the nucleotidase, raises the question as to whether the well-known therapeutic effects of nicotinamide may not be due partly to this action. If this view is true, substances other than nicotinamide having a similar protective effect may have similar therapeutic effects. It is interesting to note in this connexion that Vilter and Spies ${ }^{3}$ have shown that quinolinic acid will cure pellagra and that Wooley et al. ${ }^{4}$ find that a variety of nicotinic acid derivatives will cure canine black tongue. Moreover, as a result of the administration of quinolinic acid there has been found ${ }^{3}$ an increase in concentration of cozymase in the blood.

Work on this problem is still in progress and further details will be published in due course.

We are grateful to the Rockefeller Foundation and to the Medical Research Council for financial help.

$$
\text { P. J. G. MANN. }
$$

Biochemical Laboratory, Cardiff City Mental Hospital.

$$
\text { Jan. } 24 .
$$

\footnotetext{
${ }^{1}$ Quastel and Wheatley, Biochem. $J ., 32,936$ (1938).

2 Baker, Fazekas and Himwich, J. Biol. Chem., 125, 545 (1938).

- Vilter and Spies, Lancet, ii, 423 (1939).

- Wooley, Strong, Madden and Elvehjem, J. Biol. Chem., 124, 715 (1938).
}

\section{Rates of Oxidation of Isomeric Dihy- droxy- and Tetrahydroxy-stearic Acids by Lead Tetra-acetate}

Measurements of the rate of consumption of lead tetra-acetate, when used in strictly comparable conditions to oxidize various isomeric polyhydroxystearic acids, have revealed marked differences between the speed of oxidation of isomeric forms. We have observed these differences both in the two isomeric 9, 10-dihydroxystearic acids (m.p. $95^{\circ}$ and $132^{\circ}$ ) and in the four known forms of $9,10,12,13$-tetrahydroxystearic acids (m.p. $173^{\circ}, 163^{\circ}, 146^{\circ}$ and $134^{\circ}$ ). Further measurements are in progress in the group of tetrahydroxy-acids, and the complete results of this work will be reported in fuller detail later.

The data in the accompanying table show the rate of oxidation of the two 9,10-dihydroxystearic acids

\begin{tabular}{|c|c|c|}
\hline \multirow[t]{2}{*}{$\begin{array}{l}\text { Time } \\
\text { (min.) }\end{array}$} & \multicolumn{2}{|c|}{$\begin{array}{l}\text { Moles lead tetra-acetate consumed } \\
\text { per mole dihydroxystearic aeid }\end{array}$} \\
\hline & Acid m.p. $95^{\circ}$ & Acid m.p. $132^{\circ}$ \\
\hline 0.5 & $1 \cdot 23$ & $0 \cdot 10$ \\
\hline $1 \cdot 5$ & $1 \cdot 48$ & $0 \cdot 18$ \\
\hline $2 \cdot 5$ & $1 \cdot 60$ & $0 \cdot 27$ \\
\hline $3 \cdot 5$ & $1 \cdot 64$ & 0.37 \\
\hline $4 \cdot 5$ & $1 \cdot 70$ & 0.45 \\
\hline 10 & $1 \cdot 78$ & 0.64 \\
\hline 25 & $1 \cdot 87$ & $1 \cdot 05$ \\
\hline 55 & 1.95 & $1 \cdot 48$ \\
\hline 100 & $1 \cdot 97$ & $1 \cdot 72$ \\
\hline 160 & $2 \cdot 01$ & $1 \cdot 80$ \\
\hline
\end{tabular}
when each $(0.0005$ mole $)$ was oxidized in glacial acetic acid (100 ml.) containing lead tetra-acetate $\left(0 \cdot 001875\right.$ mole) at $20^{\circ}$ :

The rate of oxidation of the acid, m.p. $95^{\circ}$, is far more rapid than that of the isomeric form, m.p. $132^{\circ}$. The difference in the rate of oxidation of the two acids is similar to that of many pairs of cyclic glycols; Criegee $^{1}$ has shown, in the case of the latter geometrical isomerides, that cis-glycols are attacked by lead tetra-acetate more rapidly than the transisomerides. In the acyclic polyhydroxystearic acids, however, the stereoisomerism is that of two (racemic) asymmetric carbon atoms, and is not a case of geometrical isomerism.

Dept. of Industrial Chemistry,

T. P. Hilditoh.

University of Liverpool.

Research Laboratories,

H. JASPERSON.

Messrs. J. Bibby and Sons, Ltd., Liverpool.

Feb. 12.

${ }^{3}$ Criegee, Ber., 64, 260 (1931) ; 65, 1770 (1932). Ann., 5(7, 159 (1933).

\section{Pre-Precipitation Phenomena in Age-Hardening Alloys}

Usrng an improved X-ray technique, Preston ${ }^{1}$ and Guinier ${ }^{2}$ have shown that when aluminium-copper single crystals containing 4 per cent copper are aged at low temperatures, thin plates of copper-rich atoms are formed on (100) planes of the crystal. Swindells and Sykes $^{3}$ found, from specific heat measurements on a similar alloy, that when specimens previously aged at low temperatures were re-heated, heat was 